\title{
Language and Culture from the Communicative Perspective in the Context of Globalization
}

\author{
Jianna Qiu ${ }^{1, a}, \mathrm{Ke} X \mathrm{u}^{2, \mathrm{~b}}$ * \\ ${ }^{1}$ School of Foreign Languages, Quanzhou Normal University, Quanzhou, Fujian, China \\ ${ }^{2}$ School of Physical Education, Quanzhou Normal University, Quanzhou, Fujian, China \\ aqiujianna@163.com, ${ }^{b}$ xk7367@aliyun.com
}

Keywords: Language, Culture, Intercultural, Communication.

\begin{abstract}
This paper is to explore the inseparable relationship between language and culture from the communicative perspective in the context of globalization, with a view to raising some practical suggestions from contents to forms on English language teacher skills development.
\end{abstract}

\section{Introduction}

Language and culture are inseparable. There is no denying that a better command of corresponding cultures will result in a better understanding between non-native speakers and native speakers as well as among non-native speakers throughout the world. Therefore, great importance has been attached to the spread of culture as an inseparable part of language itself. With a view to raising some practical suggestions from contents to forms on English language teacher skills development, this paper is to explore the relationship between language and culture from the communicative perspective in the context of globalization. As illustrated by Crozet and Liddicoat (2000, p. 1), "teaching culture in language implies an acknowledgement and understanding of the links between language and culture as well as an understanding of how communication works across cultures" ${ }^{[1]}$.

\section{The Relationship between Language and Culture}

The relationship between language and culture could start with the definition of these two words. For the purpose of communication according to CARLA (n.d.) ${ }^{[2]}$, culture is defined as the patterns of behaviours and interactions, cognitive constructs, and affective understanding, which are shared and learned through a process of socialization. Based on this definition, culture is the combination of actions and ideas which are different from each other and will make changes in the light of the social development. On the other hand, according to UNIXL (n.d.) ${ }^{[3]}$, language is defined as a communicating system with sounds, symbols and words in expressing a meaning, idea or thought, used in many forms primarily through oral and written communications as well as body language (the gesture of letter "V" means victory in English, for example, which however is well known throughout the world). In this sense, language is a tool in communication with a variety of elements and forms.

From the above analysis we can see that language is an approach to exchange messages, which at the same time act as the embodiment of a certain culture. In Crozet's (2003, p. 39) words, "cultural traits as found in language use can be interpreted as the expression of meaning behind and with the word" ${ }^{\text {[4] }}$. Therefore, only with a better command of corresponding culture could the messages through the language tool be delivered and perceived in an appropriate way and hence a successful communication is achieved. The comprehensive interpretation of these two definitions provides the key reason for the teaching of culture as an inseparable part of language, since the best and profound way for people from different cultural backgrounds to communicate well with each other is to understand and negotiate the differences. In brief, language and culture, as far as communication is concerned, interact mutually during the process of English language teaching and learning, and their inseparable relationship is clear in the view that "every attempt to communicate with the speaker of another language is a cultural act” (Crozet \& Liddicoat, 2000, p. 2) ${ }^{[5]}$. 
English, as the target language in the paper, plays a vital role on the international stage. Its influences are not restricted to the academic field where research on language leaning and teaching is conducted and put into practice, but are spread to all walks of life across cultures and take an effective effect in a higher sense. In addition, it is worth pointing out that English is now more commonly used as a language of communication between non-native speakers of English who should learn and talk in English about their own cultures (Kirkpatrick, 2007, p. 23) ${ }^{[6]}$. Moreover, wherever a language is used by non-native speakers, they are involved in intercultural contexts which need interpreting (Crozet \& Liddicoat, 2000, p. 13) ${ }^{[7]}$. It does not necessarily mean that any culture traditionally associated with native speakers is not important enough, because the importance depends on different contexts and functions. Between non-native speakers and native speakers of English, the cultural traits of both sides are distinct and different. In order to realize a better communication, both cultures are worth learning. Conversely, the same is true that a better communication will correspondingly play an active role during the process of cultural acquisition. Overall, in the context of globalization, English is not regarded as one feature of western culture, but as a communicative tool in the practical sense.

\section{English Language Teacher Skills Development}

The Importance of Cultural Acquisition in English Language Teaching in Respect to Teachers of Native Speakers. Based on the multi-cultural feature of English, the primary role that English plays is as a lingua franca (Kirkpatrick, 2007) ${ }^{[8]}$, a common language used by speakers of different languages. In accordance with this, many suggestions are offered with the emphasis on the teaching of culture as an inseparable part of language for high levels of mutual understanding.

However, the question is that rare illustration is demonstrated about the need for native speakers of English teachers, who are born to be located in the English cultural atmosphere, to learn about their own culture and the cultures of non-native speakers. In practice, it is not uncommon that some native speakers of English teachers will ignore some of their cultural points because they are too common in their lives, or have a subjective attitude towards their own culture with bias and misunderstanding towards other cultures, or be less competent in English cultural knowledge compared with some non-native speakers of English teachers. All these factors will without question lead to the problems of cultural teaching in English language. Therefore, English teachers of native speakers are required to learn about their own culture in order to have a better understanding of their own language during the process of English teaching. Other than that, it is also necessary for them to learn about the cultures of non-native speakers of English for a deep and effective communication, because in the context of globalization, the interaction among people from different cultural backgrounds is bound to happen in various fields such as politics, economy and culture throughout the world.

The Contents of Cultural Teaching in English Language. Due to its variable feature, culture fluctuates with time and space, especially with the rapid development of science and technology as well as the increase and deepening of intercultural communication, indicating that the culture in language is not easily accessible, which is regarded as the difficulty and emphasis of teaching culture as an inseparable part of language. Consequently, the way to solve the problem is that the contents of cultural teaching should be altered accordingly to make it appropriate and factual in order to keep pace with the times.

It is known to all that effective teaching is built on effective interaction between teachers and learners. In accordance with different learners, teachers should take different measures with different teaching contents. For example, the needs of English beginners are to be investigated to make themselves have a feel for the language itself, and the song of alphabet shows a perfect example. In other words, the purpose of cultural points incorporated at the beginners' stage is to set a cultural atmosphere of English. In this sense, the principle of cultural teaching should be simple in contents and relaxing in forms. However, in terms of English learners at the advanced level, the emphasis of the cultural teaching should be put on the part of communicative competence which is generally regarded as the essence of language learning. The contents to be delivered should make learners have 
a deep understanding about English culture as well as the comparison and contrast between English culture and their own.

In addition, in an intercultural approach to language teaching, the teacher becomes the principal mediator between cultures (Crozet \& Liddicoat, 2000, p. 4) ${ }^{[9]}$, and special attention must be paid to the attitudes towards cultural differences, because neither attitude in the following part is beneficial for effective teaching and learning. Overemphasizing the differences can lead to biased interpretation of a foreign culture; while underestimating the differences can mislead learners to perceive own ways as the only "normal" cultural standard and to impose their own codes on people with whom they are interacting (Li, 2003, pp. 97-98) ${ }^{[10]}$. Overall, as cultural mediators, teachers' attitudes towards cultural differences should be neutral. In other words, by means of demonstrating the differences with appropriate comparison and analysis, an objective position should be taken up during the process of teaching and learning for the purpose of high levels of mutual understanding and communication across cultures.

English Language Teacher Skills Development from the Perspective of Intercultural Language Teaching (ILT). An appropriate interpretation of Intercultural Language Teaching is that there is an urgent need for language teachers to integrate cultural perspectives into language teaching as a basic part of language teaching method. Practically speaking, the essence of English teaching and learning lies in communication, as the basic goal of language teaching is still to make language learners competent in the aspects of listening, speaking, reading and writing. In accordance with the purpose of communication which is to narrow the information gap (Morrow, 1981, p. 62) ${ }^{[11]}$ resulting from cultural differences to some extent, the task and challenge in the English classroom in consequence is to extend the horizons of both sides (Hargreaves \& Mclean, 1994, p. 159) ${ }^{[12]}$, making teachers and learners recognize, understand and enjoy the differences and development. In conclusion, the fundamental skills concerned with ILT for English language teachers are substantial and will be listed and interpreted critically according to the suggestions from previous researchers.

It should be clear that the purpose of cultural teaching as an inseparable part of language is not for the culture itself, because English language teaching is located in a certain cultural context which will take effect naturally. For example, it is widely admitted that various cultures demonstrate a variety of ideas about what is and what is not funny. Hence, the command of humor, as one of the most difficult elements in cultural context, requires a large amount of time and efforts. In brief, the function of ILT is to make learners develop skills and strategies which are used to cope with concrete circumstances and aware of the social meaning of language forms in order to communicate in an appropriate and effective way called communicative competence (Littlewood, 1981, P. 6) ${ }^{[13]}$.

As culture itself is an abstract issue, the need for culture to be incorporated into English language teaching is a highly-demanding task. It has to be admitted that the method of teaching culture as a separate part of English language teaching is not appropriate and out of date. The problem is how to incorporate culture into English language teaching naturally and effectively. As far as teachers are concerned, they function as the key role in English language teaching, so their teaching skills are vital to the teaching results. A list of skills or knowledge that all English language teachers should possess is suggested by Kirkpatrick (2007, pp. 32-33): Be multicultural; it states the background of cultural teaching as an inseparable part of language teaching. Understand how English has developed in specific contexts and how it has spread across the world; it is because of the variable feature of English language and points out the function of communication. Understand the roles of English in the community and how these interrelate with other local languages; because its function is different in different contexts, and the research on the relationship with other languages is a demonstration of communication. Be able to evaluate the specific needs of their students and teach towards those needs; to teach accordingly, which is a highly valued principle and well worth practicing by teachers of any fields all over the world. Know the context and respect local knowledge; any communication is established upon mutual understanding and equality, and there is no exception to English language teaching and learning ${ }^{[14]}$. 


\section{Conclusion}

In the context of globalization, English acts as an international language under a variety of cultures. With the development of time and space, English language makes various changes itself as well as for the needs of different speakers from different cultural backgrounds. In this circumstances, a question concerned with the development of English language itself and the English language teaching is raised that should English be taught as Standard English or as world Englishes. In spite of this, English as a communicative tool will play its indispensable role with cultures on the international stage, as indicated by White (1997, p. 9), successful intercultural communication in English will involve reframing and developing new norm through raising and refining learners' awareness as well as a process of mutual transformation ${ }^{[15]}$, by means of which, a variety of cultures are shared and integrated, high levels of mutual understanding is achieved and a harmonious society is formed, for the sake of the common goal all in all: development and peace of the entire human race.

\section{References}

[1,5,7,9] Crozet, C., \& Liddicoat, A. J. (2000). Teaching culture as an integrated part of language: implications for the aims, approaches and pedagogies of language teaching. In Liddicoat, A. J., \& Crozet, C. (Ed.), Teaching Languages, Teaching Cultures. Melbourne: Language Australia, pp. 1-13.

[2] What is culture. (n.d.). CARLA. Retrieved April 6, 2015, from http://www.carla.umn.edu/culture/definitions.html

[3] Language definition. (n.d.). UNIXL. Retrieved April 6, 2015, from http://www.unixl.com/dir/education/languages/language_definition/

[4] Crozet, C. (2003). A conceptual framework to help teachers identify where culture is located in language use. In Bianco, J. L., \& Crozet, C. (Ed.), Teaching Invisible Culture: Classroom Practice and Theory. Melbourne: Language Australia, p. 39.

[6,8,14] Kirkpatrick, A. (2007). Teaching English across cultures: What do English language teachers need to know how to teach English. English Australia, 23(2), 20-36.

[10] Li, K. (2003). Chinese. In Bianco, J. L., \& Crozet, C. (Ed.), Teaching Invisible Culture: Classroom Practice and Theory. Melbourne: Language Australia, pp. 53-100.

[11] Morrow, K. (1981). Principles of communicative methodology. In Johnson, K., \& Morrow, K. (Ed.), Communication in the Classroom: Applications and Methods for a Communicative Approach. Harlow: Longman, pp. 59-66.

[12] Hargreaves, S., \& Mclean, B. (1994). The multicultural classroom. In Watson, K. (Ed.), English Teaching in Perspective. Sydney: St Clair Press, pp. 150-159.

[13] Littlewood, W. (1981). Communicative language teaching: An introduction. Cambridge: Cambridge University Press.

[15] White, R. Going round in circles: English as an international language, and cross-cultural capability. (1997). University of Reading. Retrieved April 6, 2015, from http://www.rdg.ac.uk/app_ling/circles.htm 